\title{
Nosocomial Infections in Pediatric Population and Antibiotic Resistance of the Causative Organisms in North of Iran
}

\author{
Salar Behzadnia ${ }^{1}$; Alireza Davoudi ${ }^{1}$; Mohammad Sadegh Rezai ${ }^{2}$; Fatemeh Ahangarkani ${ }^{1,}$

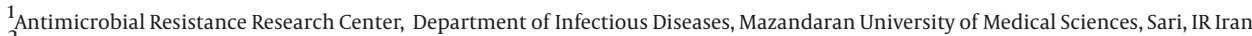 \\ ${ }^{2}$ Antimicrobial Resistant Nosocomial Infectious Research Center, Mazandaran University of Medical Sciences, Sari, IR Iran \\ ${ }^{*}$ Corresponding Author: Fatemeh Ahangarkani, Antimicrobial Resistance Research Center, Department of Infectious Diseases, Mazandaran University of Medical Sciences, Sari, IR \\ Iran. Tel: +98-1232316319 Fax:+98-1232316319, E-mail address: fkani63@gmail.com \\ Received: August 31, 2013; Revised: October 6, 2013; Accepted: October 26, 2013
}

Background: Treatment of the nosocomial infections is complicated especially in children due to an increase in the antibiotic-resistant bacteria.

Objectives: The aim of this study was to survey the nosocomial infections in children and determine the antibiotic susceptibility of their causative organisms in teaching hospitals in the north of Iran.

Patients and Methods: The investigation was designed as a retrospective cross-sectional study. The study population consisted of patients under 12 years old, which were hospitalized in three teaching hospitals in the north of Iran and had symptoms of nosocomial infections in 2012. The required data of patients were extracted and entered in the information forms. The collected data were analyzed using SPSS (ver. 16). Descriptive statistics and Fisher's exact tests (Monte Carlo) were used.

Results: Out of the total number of 34556 hospitalized patients in three teaching hospitals, 61(0.17\%) patients were children under 12 years old age with nosocomial infection from which $50.81 \%$ were girls and $49.18 \%$ were boys. Most of these patients (55.73\%) were admitted to the burn unit. The most common type of nosocomial infection (49.18\%) was wound infection. Pseudomonas spp. (36.84\%) and Acinetobacter spp. (28.02\%) were the most common bacteria isolated from the clinical specimens. All the Acinetobacter spp. were multidrug-resistant. All the gram negative and gram positive bacterial species in our study showed high resistance to antibiotics.

Conclusions: The rate of nosocomial infections was low in our study because the detection of nosocomial infection was based on the clinical grounds in most cases and laboratory reports might contain false-negative results. These results provide useful information for future large scale surveillance in the context of prevention programs.

Keywords:Infection; Children; Iran

\section{Background}

Nosocomial infections (NIs) remain a major problem in the health care centers across the world and leads to high mortality. NIs exist in a worldwide fashion. Globally, $8.7 \%$ of the hospitalized patients are affected with NIs. These infections cause death, failure of surgeries, rejection of transplanted organs, failure of chemotherapies and increasing costs for patients and health centers, a longer stay in the hospital and mental and emotional stress (13). In Europe, the incidence of NIs in the general children ward is $1 \%$ and in the neonatal intensive care units have been reported to be $23.6 \%$ (2). The most common type of NIs in children are bloodstream infections, pneumonia (ventilator-associated VAP), urinary tract infections (UTI), skin and surgical site infections (1). Organisms such as gram-negative bacilli, coagulase-negative staphylococci, coagulase-positive staphylococci, pseudomonas spp, and streptococcus are the main causes of NIs. A common prob- lem in the treatment of NIs in pediatric wards in hospitals is increasing frequency of antibiotic-resistant organisms. Surveillance activities are the first step in developing infection control programs and may help in decreasing the incidence of infections and reducing costs (2). However there is a significant knowledge gap regarding the NIs due to the lack of enough data from the epidemiological studies: the reports coming from Iran are not enough and there has not been any report of surveillance of NIs in children from the north of Iran.

\section{Objectives}

The purpose of this study is survey of NIs and antibiotic susceptibility patterns of causative agents among the children admitted to the teaching hospitals affiliated with the Mazandaran University of Medical Sciences in order to help the physicians in choosing better antibiotics for the empiric therapy of these infections.

Implication for health policy/practice/research/medical education:

Surveillance activities are the first step in developing infection control programs. No report is available regarding the surveillance of nosocomial infections in children of the north of Iran. The purpose of this study is to provide a survey of nosocomial infections and antibiotic susceptibility patterns of causative agents among the children admitted to the teaching affiliates of the Mazandaran University of Medical Sciences in order to help the physicians in choosing the better types of antibiotics for the empiric therapy of these infections.

Copyright (C) 2014, Iranian Red Crescent Medical Journal; Published by Kowsar Corp. This is an open-access article distributed under the terms of the Creative Commons Attribution License, which permits unrestricted use, distribution, and reproduction in any medium, provided the original work is properly cited. 


\section{Patients and Methods}

This was a cross sectional-retrospective study. The location of study was the general pediatric wards, NICU and burn wards of three teaching hospitals of the Mazandaran University of Medical Sciences (in north of Iran) including the Bu Ali Sina hospital, Shahid Zare Hospital and Razi hospital. This study was approved by the Ethics Committee of Mazandaran University of Medical Sciences (Code No: 9134, Date: July 11, 2012). Census method was performed for sampling. The study population included the children under 12 years old, hospitalized in these hospitals in 2012 who had symptoms of NIs. Infections (based on National Directory of Nosocomial Infections Surveillance System) (4), were defined as:

UTI: The patient must have at least one of the symptoms such as fever, dysuria, frequency, flank pain, suprapubic pain, nausea and vomiting plus positive urine culture or must at least have two symptoms such as fever, dysuria, frequency, flank pain, suprapubic pain, nausea and vomiting plus pyuria.

Wound Infection: Superficial surgical site infection is identified with at least one of the following characteristics: purulent discharge from the wound, organisms isolated from the fluid or superficial surgical tissue that should aseptic, at least one of the symptoms such as pain, swelling, redness or warmness, or diagnosis of the wound infection by the doctor. Respiratory Infection: Crackles on lung examination or radiographic findings plus at least one of the following: purulent sputum or positive blood culture or positive culture of the tracheal aspirate sample. Blood Infection: Blood culture grows a pathogenic organism, condition that is not related to the location of a localized infection or having fever, chills, decreasing blood pressure plus existing infections related to the skin in at least two blood culture samples (like diphtheroids, bacillus species, propionibacterium or coagulase negative staph).

Identification of the organisms causing infection were performed according to the standard microbiological procedures (5, 6). Antimicrobial susceptibility testing method, the disk diffusion (Kirby-Bauer) were performed according to the standard CLSI2010 (7). We gathered information from the demographic and clinical characteristics, risk factors, medical history, main diagnosis, type of NIs, type of the culture and entered them in the data forms. Then, the collected data were analyzed using SPSS software (ver. 16). Descriptive statistics and Fisher's exact tests (Monte Carlo) were used for the statistical analysis.

\section{Results}

From the total of 34556 hospitalized patients in three teaching hospitals, $61(0.17 \%)$ patients were children under age 12 with NIs, from whom 31 were girls (50.81\%) and 30 were boys (49.18\%). The average age was $6 \pm 4.32$ (range 1 day, 12 year) years old. The average duration of hospitalization was 7 (range, 2-35) days. The most prevalent types of NIs were wound infection (50.81\%, 95\%:CI37.9-63.7), respiratory infection (21.31\%, 95\%CI: 10.7-31.8), UTI (19.67\%, 95\%CI: 9.4-29.9) and blood Infection (8.19\%, 95\% CI:1.1-15.2), respectively. The prevalence of NIs in various wards is shown in Figure 1 and the demographic features, clinical characteristics and risk factors for each type of infection are described in the Table 1 . The incidence of various causative organisms for NIs is listed in Table 2. Antibiotic sensitivity patterns of the bacteria that cause NIs are listed in Tables 3 and 4 .

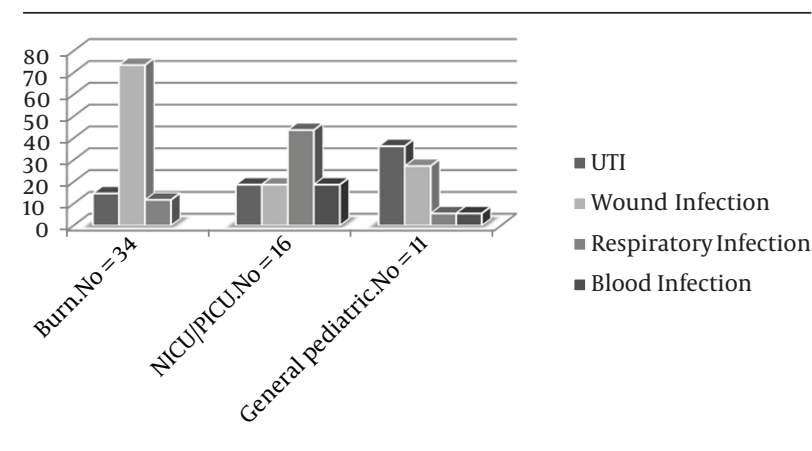

Figure 1. Distribution of Patients According to the Types of NIs by the Ward Type $(\mathrm{P}=0.273)$

Table 1. Demographic Features, Clinical Characteristics and Risk Factors of Infection

$\left.\begin{array}{llll}\hline & \begin{array}{l}\text { Wound Infection, } \begin{array}{l}\text { Respiratory Infection, Urinary tract Infection, Blood Infection, } \\ \text { No. }(\%)\end{array} \\ \text { No. }(\%)\end{array} & - & - \\ \hline \text { Gender } & - & - & 9(75)\end{array}\right)$


Behzadnia S et al.

\begin{tabular}{|c|c|c|c|c|}
\hline Urine catheter & - & - & $9(75)$ & - \\
\hline Steroid therapy & $1(3.2)$ & - & - & - \\
\hline Symptoms & - & - & - & - \\
\hline Fever & $26(83.87)$ & $13(100)$ & $12(98.4)$ & $5(100)$ \\
\hline Dysuria & - & - & $9(75)$ & - \\
\hline Frequent urination & - & - & $9(75)$ & - \\
\hline Flank pain & - & - & $7(58.3)$ & - \\
\hline Suprapubic pain & - & - & $8(66.7)$ & - \\
\hline Nausea & - & - & - & - \\
\hline Vomiting & - & - & - & - \\
\hline Chest pain & - & - & - & - \\
\hline Cough & - & $10(76.9)$ & - & - \\
\hline Increase of sputum & - & $5(35.8)$ & - & - \\
\hline dyspnea & - & $7(53.8)$ & - & - \\
\hline Wound erythema & $29(93.5)$ & - & - & - \\
\hline Wound oozing & $24(77.4)$ & - & - & - \\
\hline Suture openings & $21(67.70)$ & - & - & - \\
\hline
\end{tabular}

Table 2. Causative Agents of Infections

\begin{tabular}{llllll}
\hline & $\begin{array}{l}\text { Wound Infection, Respiratory Infection, } \\
\text { No. }(\%)(\mathbf{n o}=\mathbf{3 0})\end{array}$ & $\begin{array}{l}\text { Urinary Tract Infection, }(\mathbf{n})(\mathbf{n o}=\mathbf{1 3}) \\
\text { No. }(\%)(\mathbf{n o}=\mathbf{9})\end{array}$ & $\begin{array}{l}\text { Blood Infection, } \\
\text { No. }(\%)(\mathbf{n o}=\mathbf{5})\end{array}$ & $\begin{array}{l}\text { Total, No. (\%) } \\
(\mathbf{n o}=\mathbf{5 7})\end{array}$ \\
\hline Pseudomonas.spp & $12(40)$ & $4(30.76)$ & $3(33.33)$ & $2(40)$ & $21(36.84)$ \\
Acinetobacter.spp & $10(33.33)$ & $6(46.15)$ & 0 & 0 & $16(28.07)$ \\
E. coli & 0 & 0 & $4(44.44)$ & 0 & $4(7.01)$ \\
C. freundii & $2(6.66)$ & 0 & 0 & 0 & $2(3.50)$ \\
Enterobacter.spp & $2(6.66)$ & 0 & 0 & $1(20)$ & $3(5.26)$ \\
Klebsiella.spp & 0 & $2(15.38)$ & 0 & $1(20)$ & $3(5.26)$ \\
S.Marcescens & 0 & $1(7.69)$ & 0 & 0 & $1(1.75)$ \\
S. aureus & $2(6.66)$ & 0 & 0 & 0 & $2(3.50)$ \\
S. saprophyticus & $2(6.66)$ & 0 & 0 & $1(20)$ & $3(5.26)$ \\
C.albicans & 0 & 0 & $2(22.22)$ & 0 & $2(3.50)$ \\
\hline
\end{tabular}

Table 3. Antibiotic Susceptibility of Gram Negative Bacteria Isolated From Infection Sites

\begin{tabular}{|c|c|c|c|c|c|c|c|c|c|c|c|c|c|c|}
\hline \multirow[t]{2}{*}{ Antibiotics } & \multicolumn{2}{|c|}{$\begin{array}{l}\text { C.Freundii, } \\
(\%)(\text { no }=2)\end{array}$} & \multicolumn{2}{|c|}{$\begin{array}{c}\text { S.Marcescens, } \\
(\%)(\mathrm{no}=1)\end{array}$} & \multicolumn{2}{|c|}{$\begin{array}{c}\text { E.coli, (\%) } \\
(\text { no }=4)\end{array}$} & \multicolumn{2}{|c|}{$\begin{array}{c}\text { Klebsiella. } \\
\text { spp, }(\%)(\text { no }=3)\end{array}$} & \multicolumn{2}{|c|}{$\begin{array}{c}\text { Enterobacter. } \\
\text { spp },(\%)(\text { no }=3)\end{array}$} & \multicolumn{2}{|c|}{$\begin{array}{l}\text { Acinetobacter. } \\
\text { spp },(\%)(\mathrm{no}=16)\end{array}$} & \multicolumn{2}{|c|}{$\begin{array}{c}\text { Pseudomonas. } \\
\text { spp, }(\%)(\text { no }=21)\end{array}$} \\
\hline & $\mathbf{R}^{\mathrm{a}}$ & $\mathbf{I}^{\mathrm{a}}$ & $\mathbf{R}$ & I & $\mathbf{R}$ & I & $\mathbf{R}$ & I & $\mathbf{R}$ & I & $\mathbf{R}$ & I & $\mathbf{R}$ & I \\
\hline Ceftriaxone & - & 100 & - & - & 100 & - & - & 100 & - & 33.3 & 100 & - & 94.4 & 5.6 \\
\hline Ceftizoxime & 50 & 50 & 100 & - & - & 100 & - & 100 & 66.6 & - & 100 & - & 42.85 & 19.33 \\
\hline Ceftazidime & 50 & 50 & - & 100 & 100 & - & 66.6 & 33.3 & - & 66.6 & 100 & - & 33.3 & - \\
\hline Cefixime & 50 & 50 & 100 & - & - & 50 & - & 100 & 66.6 & 33.3 & 100 & - & 11.1 & - \\
\hline Carbenicillin & - & 100 & 100 & - & - & 100 & - & 100 & 66.6 & 33.3 & 100 & - & 42.85 & - \\
\hline Ampicillin & 100 & - & 100 & - & 100 & - & 100 & & 66.6 & 33.3 & 100 & - & 57.14 & 4.7 \\
\hline Ciprofloxacin & 50 & 50 & - & - & 100 & - & - & 100 & 100 & - & 100 & - & 94.4 & 5.6 \\
\hline Norfloxacin & - & 100 & - & - & 100 & - & - & 100 & 100 & - & 100 & - & 42.8 & - \\
\hline Nalidixic Acid & 100 & - & - & 100 & 100 & - & 66.6 & 33.3 & - & 100 & 100 & - & 23.8 & - \\
\hline Gentamicin & - & 100 & - & - & 100 & - & 66.6 & - & 100 & - & 100 & - & 42.85 & 19.33 \\
\hline Amikacin & - & 100 & - & - & - & 25 & - & - & - & 100 & 100 & - & 50 & - \\
\hline Imipenem & - & 100 & - & - & 100 & - & 100 & - & - & - & 100 & - & 38.9 & - \\
\hline Co-trimoxazole & 100 & - & - & 100 & 75 & 25 & - & 100 & 100 & - & 100 & - & 80.95 & \\
\hline Tetracycline & - & 100 & 100 & - & 100 & - & - & 100 & 100 & - & 100 & - & 71.42 & \\
\hline
\end{tabular}

a Abbreviations: R: Resistant to antibiotics; I: Intermediate sensitivity to antibiotics 
Behzadnia S et al.

\begin{tabular}{|c|c|c|c|c|}
\hline \multirow[t]{2}{*}{ antibiotics } & \multicolumn{2}{|c|}{ S. aureus, $(\%)($ no $=2)$} & \multicolumn{2}{|c|}{ S. saprophyticus, $(\%)(\mathrm{no}=3)$} \\
\hline & $\mathbf{R}^{\mathrm{a}}$ & $\mathbf{I}^{\mathrm{a}}$ & $\mathbf{R}$ & $\mathbf{I}$ \\
\hline Ampicillin & 100 & - & 100 & - \\
\hline Carbenicillin & 100 & - & 33 & - \\
\hline Penicillin & 100 & - & 100 & - \\
\hline Oxacillin & 100 & - & 66 & - \\
\hline Cefazolie & 100 & - & 100 & - \\
\hline Ceftriaxone & - & - & 66 & - \\
\hline Ceftizoxime & - & 50 & 100 & - \\
\hline Ciprofloxacin & 100 & - & 100 & - \\
\hline Vancomycin & - & - & - & - \\
\hline Clindamycin & - & 50 & - & - \\
\hline Erythromycin & 100 & - & 66 & - \\
\hline Co-trimoxazole & 100 & - & 100 & - \\
\hline Tetracycline & 100 & - & 66 & - \\
\hline
\end{tabular}

${ }^{\mathrm{a}}$ Abbreviations: R: Resistant to antibiotics; I: Intermediate resistance to antibiotics

\section{Discussion}

The rate of NIs in our study was lower than other studies. The following points need to be considered. NIs detection was based on the clinical grounds in most of our cases; which raises the possibly of missing patients with subclinical infections and also might be due to the fact that laboratory reports might contain many false-negative results. Absence of facilities for culture of anaerobic bacteria in the north of Iran, low NIs reporting from wards, early discharge of the patients undergoing surgery, and lack of follow up in NIs patients referred to clinics, all can be a cause of falsely low reported rate of NIs. In this study, most of our patients were hospitalized in burn unit and most common type of NIs was wound infection which is consistent with earlier studies (8-10). The most common bacteria isolated from patients in this ward (burn unit) were P. Aeruginosa and Acinetobacter spp. The type of bacteria isolated from wound samples in Oncul et al. study was similar to our research (11). In Javanbakht et al. study in Mashhad, the highest frequency of cross infection was in burn ward and Acinetobacter spp. was the most frequent pathogen, which is different from our results. The high incidence of Acinetobacter spp. in their study may be due to the abundance of dry soil in Mashhad which is the origin of Acinetobacter (12). In the study of Coetzee et al. $44.81 \%$ of the isolated organisms from pediatric patients admitted to the burn unit was P. Aeruginosa which is similar to our findings (13). We observed that the most important risk factors in patients with wound infection were diabetes mellitus and use of steroids. The increased susceptibility to wound infection in diabetic patients is an established risk factor for NIs (14). Also, development of NIs was associated with the use of steroids in Rojas study (15).
We found that $26.20 \%$ of NIs patients were admitted to NICU/PICU and respiratory infection (43.75\% of NIs cases) was the most common NIs in this ward followed by UTI, Blood infection and wound infection. Due to frequent airway suctioning, contamination of nurses' hands are major causes of respiratory NIs in this ward. In Raymond et al. study the rate of lower respiratory tract infections in PICU was 53\%. Conversely, Pourakbari et al. reported the rate of respiratory tract infections to be $36 \%(2,3)$. We noted that in our study there was no case of ventilator associated pneumonia was found; the fact that the ventilator was not used at all is one of reasons for the lower prevalence of respiratory infections in our study compared to other studies. Prevalence of NIs varies in different regions, for example, studies in the United States has shown that the incidence of NIs in NICU varied from 5.26 $\%$ to $12 \%$, but Abdel-Wahab et al. in Egypt, reported the incidence of NIs in the NICU to be $21.4 \%$ and in the Salamati et al. study prevalence of NIs was $40 \%$ (16-18). Comparing Salamati et al. results with our findings, the prevalence of NIs in NICU/PICU in our study was lower. Also, the types of NIs in their study were different from our results. We did not observe $S$. aurues in patients hospitalized in NICU/ PICU in contrast to Salamati et al. study. In the general pediatric ward, the prevalence of NIs was $18.53 \%$ in our study. A total of $19.67 \%$ of patients in our study had UTI, from which $12.9 \%$ of patients with UTI were hospitalized in the general ward, which was consistent with reports of Pourakbari, Balat and Abdolioskouie (2, 3, 19, 20). The most common risk factor for UTI was urinary catheter (73.8\%) consistent with Dashtbozorg et al. study (21). In our study we observed that the most causative agent 
of UTI was E.coli; according to many studies in Iran, the main cause of UTI is still E. coli $(22,23)$. We reported that 8.19 \% (3 cases in NICU and 2 cases in General pediatric ward) of patients had nosocomial blood infection. These numbers were much lower than the results of Abdolioskouie (68.9\%) and Becerra (18.1\%) and are closer to the Pourakbari et al. findings (14\%). The most common bacteria isolated from the blood infections in Pourakbari et al study were gram positive bacteria, but in our study it was pseudomonas $\operatorname{spp}(1,3,20)$.

In this study, most of the isolated bacteria were Pseudomonas spp and Acinetobacter spp. Also these bacteria have been reported as the most common cause of NIs in Hsueh and Ortega studies $(24,25)$. All Acinetobacter spp. isolated from clinical specimens were multidrug-resistant. Prevalence of the multi-drug resistant Acinetobacter spp. in countries of the Atlantic region have been reported to be $29.3 \%$ (26). Unfortunately treatment of the infectious diseases caused by Acinetobacter spp. is difficult because of the increase in the prevalence of multi-drug resistant strains (27-29). Death rate resulting from NIs caused by Acinetobacter spp. have been reported to be $7.8 \%$ to $23 \%$ (26). Between $58 \%$ to $96 \%$ of Acinetobacter spp. which were the cause of NIs in Vahdani et al. study were multidrugresistant (30). Pseudomonas species isolated from clinical samples in our study have shown different but still high level resistance to third-generation cephalosporins, aminoglycosides and fluoroquinolones. Enterobacteriaceae species in our study have been shown to have high level resistance to antibiotics. E. coli, Enterobacter spp., Klebsiella spp., C. freundii, and S. marcescens have been shown to have $50 \%$ to $100 \%$ resistance rate to antibiotics. In Bean et al. study, the rate of resistance of E. coli to ampicillin, gentamicin, cotrimoxazole and ciprofloxacin, were lower than our results (31). It seems that, the high incidence of antibiotic resistance to Enterobacteriaceae in our study is due to the low number of these organisms compared to Bean et al study. In our study, resistance to amikacin was low in gram negative bacteria except Acinetobacter spp. and Pseudomonas spp.; C. freundi(100\%), E.coli (25\%) and Entrobacter. spp (100\%) were sensitive to amikacin.

S. aurous and S. saprophyticus had very high rate of antibiotic resistance. In the study of Molaabbaszadeh et al. S. aureus resistance was low for ciprofloxacin, clindamycin, and cotrimoxazole (32). In our study, all samples had (100\%) resistance to these antibiotics; however among $S$. aureus and S. saprophyticus organisms resistance to vancomycin were not observed. In Higashide study, 100\% of S. saprophyticus isolates were resistant to oxacillin, but in our study rate of oxacillin resistance was lower (33).The total rate of NIs was low in our study. Diagnosing NIs in our hospitals was mainly by physicians and according to the clinical criteria for reporting NIs, so the rate of inappropriate administration of antibiotics was very high. Therefore, microbiological findings might not have been valid because empirical treatment had already been start- ed before obtaining the samples from patients. Also, our laboratory findings are not accurate and contain many false negatives. Before starting the empiric treatment or/ and antibiotic prescription, physicians need to take into the consideration the prevalence of NIs and antibiotic resistance patterns of the bacteria (isolated from clinical specimens, air and equipments) in different wards.

\section{Acknowledgements}

The authors of this article have the utmost gratitude to the Vice-Chancellor for Research at Mazandaran University of Medical Sciences for providing financial support for this research project. We are grateful of infection control nurses of Shahid Zare hospital, Bu Ali Sina hospital and Razi hospitals for help in collecting patients' data.

\section{Author Contributions}

Study concept and design: Salar Behzadnia, Alireza Davoudi, Mohammad Sadegh Rezai, Fatemeh Ahangarkani. Acquisition of data: Salar Behzadnia, Fatemeh Ahangarkani. Analysis and Interpretation of data: Alireza Davoudi, Fatemeh Ahangarkani. Drafting of the Manuscript: Fatemeh Ahangarkani, Critical revision of the manuscript for important intellectual content: Mohammad Sadegh Rezai, Statistical analysis: Alireza Davoudi, Fatemeh Ahangarkani.

\section{Financial Disclosure}

There is no financial disclosure.

\section{Funding/Support}

This study was supported in part by grant 9134 from Vice-Chancellor for Research of the Mazandaran University of Medical Sciences.

\section{References}

1. Becerra MR, Tantalean JA, Suarez VJ, Alvarado MC, Candela JL, Urcia FC. Epidemiologic surveillance of nosocomial infections in a Pediatric Intensive Care Unit of a developing country. BMC Pediatr. 2010;10:66.

2. Raymond J, Aujard Y. Nosocomial infections in pediatric patients: a European, multicenter prospective study. European Study Group. Infect Control Hosp Epidemiol. 2000;21(4):260-3.

3. Pourakbari B, Rezaizadeh G, Mahmoudi S, Mamishi S. Epidemiology of nosocomial infections in pediatric patients in an Iranian referral hospital. J Prev Med Hyg. 2012;53(4):204-6.

4. Masoumi A. directory of nosocomial infections surveillance system. 2th edition edTehran: The center of management of contagious diseases: Ministry of Health and Medical Education of Islamic Republic of Iran; 2007.

5. Koneman E, Allen S, Janda W, Schreckenberger R, Winn W. Introduction to microbiology. Part II: Guidelines for the collection transport, processing analysis and reporting of culture from specific specimen sources.Philadelphia: Lippincott-Raven; 1997.

6. Collee JG, Miles RS, Watt B. Tests for the identification of bacteria. Mackie and McCartney. Practical Medical Microbiolog. 14th edLondon: Churchill Livingstone; 1996.

7. Performance Standards for Antimicrobial Susceptibility Testing: Twentieth Informational Supplement. Twent Informational Suppl. 
2010;29:1-60.

8. Horan TC, Gaynes RP, Martone WJ, Jarvis WR, Emori TG. CDC definitions of nosocomial surgical site infections, 1992: a modification of CDC definitions of surgical wound infections. Infect Control Hosp Epidemiol. 1992;13(10):606-8.

9. Martins MA, Franca E, Matos JC, Goulart EM. [Post-discharge surveillance of children and adolescents treated for surgical site infections at a university hospital in Belo Horizonte, Minas Gerais State, Brazil]. Cad Saude Publica. 2008;24(5):1033-41.

10. Alaghehbandan R, Azimi L, Rastegar Lari A. Nosocomial infections among burn patients in Teheran, Iran: a decade later. Ann Burns Fire Disasters. 2012;25(1):3-7.

11. Oncul O, Ulkur E, Acar A, Turhan V, Yeniz E, Karacaer Z, et al. Prospective analysis of nosocomial infections in a burn care unit, Turkey. Indian J Med Res. 2009;130(6):758-64

12. Javanbakht A, Askari E, Danesh L, Moghadas N, Mostafavi I, Naderinasab M. The incidence of cross infections in Imam Reza hospital, Mashhad, Iran. Iran J Microbiol. 2012;4(4):177-9.

13. Coetzee E, Rode H, Kahn D. Pseudomonas aeruginosa burn wound infection in a dedicated paediatric burns unit. S Afr JSurg. 2013;51(2):50-3.

14. Colin J. Diabetic skin and soft tissue infections. Current Opinion in Infectious Diseases. 1994;7(2):214-8.

15. Rojas MA, Efird MM, Lozano JM, Bose CL, Rojas MX, Rondon MA, et al. Risk factors for nosocomial infections in selected neonatal intensive care units in Colombia, South America. J Perinatol. 2005;25(8):537-41.

16. Gaynes RP, Edwards JR, Jarvis WR, Culver DH, Tolson JS, Martone WJ. Nosocomial infections among neonates in high-risk nurseries in the United States. National Nosocomial Infections Surveillance System. Pediatrics. 1996;98(3 Pt 1):357-61.

17. Salamati P, Rahbarimanesh AA, Yunesian M, Naseri M. Neonatal nosocomial infections in Bahrami Children Hospital. Indian JPediatr. 2006;73(3):197-200.

18. Abdel-Wahab F, Ghoneim M, Khashaba M, El-Gilany AH, AbdelHady D. Nosocomial infection surveillance in an Egyptian neonatal intensive care unit. J Hosp Infect. 2013;83(3):196-9.

19. Balat A, Hill LL. Nosocomial Urinary Tract Infections in Children. Turk J Med Sci.1999;29:51-8.

20. Oskouie SA, Rezaee MA, Ghabili K, Firoozi F. An Epidemiological Study of Nosocomial Infections in Tabriz Children's Hospital Based on National Nosocomial Infection Surveillance System (NNIS). Life Sci J. 2013;10(1):277-9.

21. Dashtbozorg A, Mahdinasab A, Latif M, Fakour M. Prevalence of infection after surgery of FX fixation In patients hospitalized in the orthopedic ward of Ahvaz Razi hospital. Jundishaour Med J.
2008;56:45-51

22. Sharifi M. Bacteriuria due to application of urinary catheter in the neurosurgery ward of Taleghani hospital of Kermanshah. $J$ Tabriz Uni Med Sci. 2009;51(35):45-51.

23. Aminizadeh Z, Kashi MS. Prevalence of multi-drug resistance and pandrug resistance among multiple gram-negative species: experience in one teaching hospital, Tehran, Iran. Int Res J Microbiol. 2011;2:90-5.

24. Hsueh PR, Teng LJ, Chen CY, Chen WH, Yu CJ, Ho SW, et al. Pandrug-resistant Acinetobacter baumannii causing nosocomial infections in a university hospital, Taiwan. Emerg Infect Dis. 2002;8(8):827-32.

25. Ortega B, Groeneveld AB, Schultsz C. Endemic multidrug-resistant Pseudomonas aeruginosa in critically ill patients. Infect Control Hosp Epidemiol. 2004;25(10):825-31.

26. Falagas ME, Kasiakou SK, Rafailidis PI, Zouglakis G, Morfou P Comparison of mortality of patients with Acinetobacter baumannii bacteraemia receiving appropriate and inappropriate empirical therapy. J Antimicrob Chemother. 2006;57(6):1251-4.

27. Falagas ME, Rafailidis PI. Attributable mortality of Acinetobacter baumannii: no longer a controversial issue. Crit Care. 2007;11(3):134.

28. Karageorgopoulos DE, Kelesidis T, Kelesidis I, Falagas ME. Ti gecycline for the treatment of multidrug-resistant (including carbapenem-resistant) Acinetobacter infections: a review of the scientific evidence. J Antimicrob Chemother. 2008;62(1):45-55.

29. Levin AS, Barone AA, Penco J, Santos MV, Marinho IS, Arruda EA, et al. Intravenous colistin as therapy for nosocomial infections caused by multidrug-resistant Pseudomonas aeruginosa and Acinetobacter baumannii. Clin Infect Dis. 1999;28(5):1008-11.

30. Vahdani P, Yaghoubi T, Aminzadeh Z. Hospital acquired antibi otic-resistant acinetobacter baumannii infections in a 400-bed hospital in Tehran, Iran. Int J Prev Med. 2011;2(3):127-30.

31. Bean DC, Krahe D, Wareham DW. Antimicrobial resistance in community and nosocomial Escherichia coli urinary tract isolates, London 2005-2006. Ann Clin Microbiol Antimicrob. 2008;7:13.

32. Mollaabaszadeh H, Mobin H, Mirzaei M. Determine the prevalence and patterns of antibiotic resistance in Staphylococcus aureus strains isolated from Emam Reza and Tabriz Shohada hospital patients. J Microb Biotech Res. 2012;3(9):45-50.

33. Higashide M, Kuroda M, Omura CT, Kumano M, Ohkawa S, Ichimura S, et al. Methicillin-resistant Staphylococcus saprophyticus isolates carrying staphylococcal cassette chromosome mec have emerged in urogenital tract infections. Antimicrob Agents Chemother. 2008;52(6):2061-8. 